\title{
Association between fat taste sensitivity and diet quality in healthy male Turkish adults
}

\author{
Elif Esra OZTURK ${ }^{1}$ (D), Derya DIKMEN ${ }^{1 *}$
}

\begin{abstract}
The aim of this study was to evaluate the relationship between fat taste sensitivity, food intake and diet quality in 41 male adults, aged 19-54 years, without any eating disorders. Food consumption in five consecutive days was recorded to evaluate food intake, and diet quality was assessed by Health Dietary Indicator-2015. Fat taste thresholds were evaluated with 3-Alternative Forced Choice Methodology. The mean fat taste threshold of the hypersensitive and hyposensitive individuals were $1.48 \pm 0.30 \mathrm{mM}$ and $7.87 \pm 0.61 \mathrm{mM}$, respectively. Hypersensitive individuals had lower energy, dietary fat, monounsaturated fatty acid, polyunsaturated fatty acid intake and energy rate from dietary fat $(\mathrm{p}<0.05)$. Health Dietary Indicator-2015 score was higher in hypersensitives than hyposensitives $(p<0.05)$. Body weight, body mass index and waist circumference were lower in hypersensitive individuals $(p<0.05)$. These findings show that fat taste sensitivity plays an important role in food intake and diet quality in individuals without eating disorders.
\end{abstract}

Keywords: fat taste sensitivity; fat taste threshold; food intake; diet quality.

Practical Application: Study results indicate the possibility of a relationship between Health Dietary Indicator and fat taste threshold. Decreased fat taste sensitivity was shown to increase dietary energy density, decrease diet quality and lead to greater fat consumption. Results of this study can be utilized for further taste related studies.

\section{Introduction}

The perception of taste has an important effect on food choice. The main function of the taste system is to prepare food for digestion and determine whether the food is safe for consumption (Liu et al., 2016). There are five basic tastes: sweet, salty, sour, bitter and umami (monosodium glutamate) (Besnard et al., 2016). Recently, there has been evidence to suggest fat as a distinct taste, together with the five basic tastes (Besnard et al., 2016; Keast \& Costanzo, 2015). The identification of fatty acid receptors located within taste bud cells in the tongue (CD 36, G-protein-coupled receptors) and the stimulation of taste nerves by these cells provide the basis for considering fat as an alimentary taste (Cartoni et al., 2010; Gilbertson, 1998; Poette et al., 2014). Manipulating dietary fat intake and therefore FFAR4 expression might help to reduce taste-mediated passive overconsumption of high fat foods (Costanzo et al., 2019).

The sense of taste functions as a nutrient-sensing system, and any irregularity may lead to excessive energy intake (Liu et al., 2016). Comparison of dietary practices in obese and normal-weight individuals has demonstrated that obese individuals prefer diets with more fat (Keast \& Costanzo, 2015). With the long-term consumption of a high-fat diet, fat taste sensitivity diminishes in the oral cavity and gastrointestinal tract, causing greater fat and food consumption to induce satiety response in the gastrointestinal system. With the long-term consumption of a low-fat diet, fatty acid sensitivity increases in the oral cavity and gastrointestinal system, and the amount of fat needed to induce satiety response decreases, leading to a reduction in body mass index (Newman et al., 2016a). The hypothesis about the link between fat taste and body mass index underlines the cause of reduced-fat sensitivity in obese individuals due to excessive fat consumption (Stewart et al., 2011a).

Taste sensitivity is important for maintaining good health (Okayama \& Watanabe, 2019). Changing fat taste sensitivity can lead to increased or decreased consumption of fatty foods and these changes may affect macronutrient composition in dietary intake and diet quality. Although there are several studies on fat taste sensitivity and food intake (Keast et al., 2014; Newman et al., 2016b; Stewart et al., 2010, 2011a), the literature on fat taste sensitivity and diet quality is still not clear. The aim of this study was to investigate the association between fat taste sensitivity, food intake and diet quality in male adults.

\section{Materials and methods}

\subsection{Subjects}

Forty-one male subjects aged 19-54 participated in this study. Subjects were recruited through campus advertisements in Hacettepe University and its vicinity in Ankara. Inclusion criteria of the study comprised non-smoking men without any metabolic or chronic diseases. Individuals with eating difficulty or swallowing disorder or an eating disorder diagnosed by the Eating Attitude Test-26 (EAT 26) or a body mass index below $18.5 \mathrm{~kg} / \mathrm{m}^{2}$ and above $30.0 \mathrm{~kg} / \mathrm{m}^{2}$ were excluded from the study. 
In addition, the study was conducted with men as women's taste sense changes during their menstrual cycles.

\subsection{Ethics}

The present study was conducted according to the guidelines of the Declaration of Helsinki, and all protocols of the study were approved by the Hacettepe University Ethics Board (GO 17/331). All subjects were informed, and their written consent was obtained before participating in the study.

\subsection{Study outline}

The study was carried out in three meetings with the subjects. In the first meeting, Eating Attitude Test-26 (EAT 26) was administered, and the subjects at risk of eating disorders were diagnosed by EAT-26 and excluded from the study. In the second meeting, subjects were told to maintain records of their food consumption for five consecutive days and informed about how to keep record in their diaries. In the second meeting, subjects were also queried about their nutritional habits: "What is the amount of oil used in your meals? (fat free, low fat, moderate fat, high fat)," "What type of oil do you prefer most in your meals? (sunflower oil, olive oil, butter, hazelnut oil)," and "What is your favorite taste? (sweet, salty, sour, bitter)." These questions were administered by the researcher through face-to-face interviews. The diaries that included the food consumption records were collected from the subjects. The third meeting was held 15 days later. In the third meeting, body weight and body compositions were measured by a dietician. Subject taste thresholds were analyzed by the ascending series three alternative forced choice methodology (3-AFC) (Figure 1).

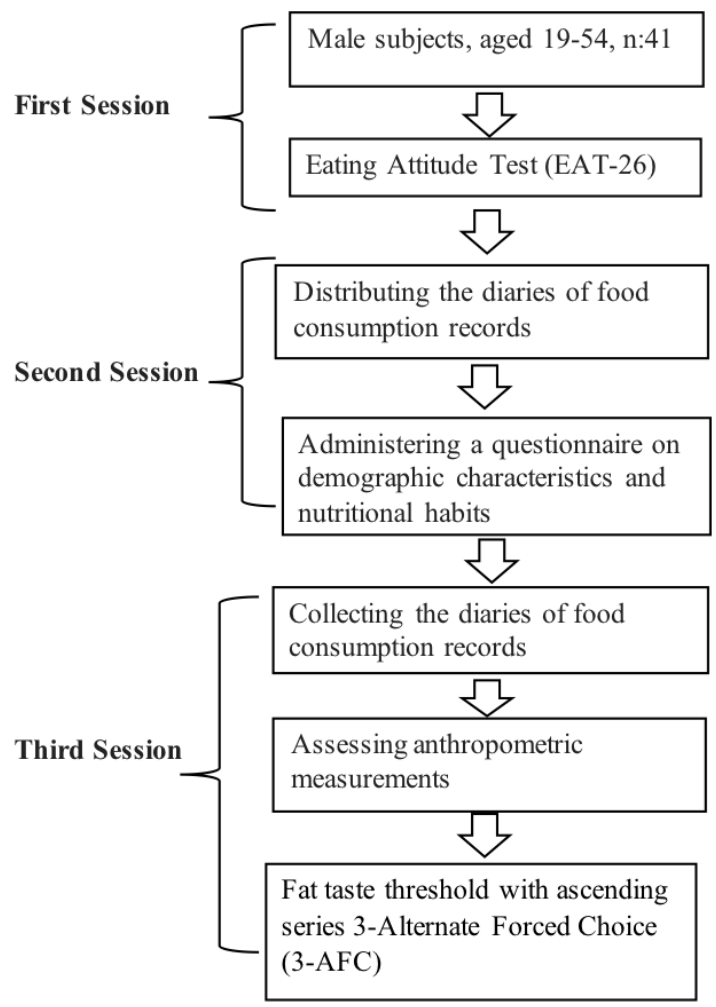

Figure 1. General plan of the study.

\subsection{Eating attitudes test}

The EAT-26 (Garner et al., 1982) is a 26-item self-report questionnaire abbreviated from the 40 -item original inventory designed to identify abnormal eating habits (Garner \& Garfinkel, 1979). To complete the EAT-26, subjects rate their agreement with statements about weight and food.

The questions relate to attitudes, beliefs and behaviors concerning food, body shape, and weight. Scale score ranges from 0 to 78. Subjects rate the intensity of their attitudes from six possible options: Never (0), Rarely (0), Sometimes (0), Often (1), Very Often (2), and Always (3). The first three responses are scored zero, and the other three responses are scored 1, 2, and 3, respectively. A score greater than 20 is considered an indicator of a possible eating disorder. Subjects who scored 20 or higher were excluded from the study.

\subsection{Diet quality}

The subjects were asked to keep food consumption records for five consecutive days ( 3 weekdays and 2 weekend days) to measure their diet quality. They were instructed, where possible, to weigh the foods they consumed or use measuring cups, spoons or common serving sizes (e.g., one slice of bread) and to be specific, such as reporting the brand of the food consumed, the type of food (e.g., white or wholemeal bread), whether they added fat (e.g., oil or butter) and the cooking methods (e.g., baking, frying, or steaming). If the food consumed was from a recipe, the subjects were asked to include the recipe with the record and to state how much of it they consumed (for example, all or half).

The Healthy Diet Indicator (HDI-2015) (Kanauchi \& Kanauchi, 2018), based on adherence to the 2015 World Health Organization (WHO) nutrition guideline, was used to measure diet quality on the basis of nutrient intake from five-day dietary records. HDI-2015 assesses 7 components: fruits and vegetables ( $\geq 400 \mathrm{~g} /$ per day), fat for total energy $(<30 \%)$, saturated fatty acid for total energy $(<10 \%)$, polyunsaturated fatty acids for total energy (6-11\%), free sugar for total energy $(<10 \%)$, dietary fiber ( $\geq 25 \mathrm{~g} /$ day), and potassium ( $\geq 3500 \mathrm{mg} /$ day). If the nutrient intake amount was within the recommended range, a score of 1 , if not, a score of 0 were assigned. HDI-2015, calculated as the sum of 7 component scores, was classified as low adherence (0-3), moderate adherence (4-5) and high adherence (6-7) (Okayama \& Watanabe, 2019).

\subsection{Anthropometric measurements}

Body weight, height, fat mass, fat-free mass, body composition and waist/hip circumferences were measured, and waist/hip circumferences and waist/height ratios were calculated. All anthropometric measurements were conducted by a dietician. The TANITA Body Composition Analyzer TBF 300 was used to measure body weight and body composition. Body mass index (BMI) was calculated (in $\mathrm{kg} / \mathrm{m}^{2}$ ) using the equation body weight $(\mathrm{kg}) /$ height $^{2}\left(\mathrm{~m}^{2}\right)$. The evaluation of body mass index was based on BMI intersection values recommended by the WHO (World Health Organization, 2020). 


\subsection{Fat taste sensitivity}

The ascending series 3-Alternative Forced Choice methodology (3-AFC) was administered to detect the subjects' fat taste thresholds (Haryono et al., 2014; Keast et al., 2014; Kindleysides et al., 2017; Running, 2015; Stewart et al., 2010, 2011a; Tucker \& Mattes, 2013). Oleic acid (C 18:1, n-9) (Sigma-Aldrich oleic acid, Ph., Eur.) was used as a stimulator in detecting fatty acid thresholds. As it is liquid, oleic acid is easily used at room temperature. Furthermore, its oxidation sensitivity is low. The oleic acid was stored at $-20^{\circ} \mathrm{C}$ until the experimental day (Kindleysides et al., 2017; Laugerette et al., 2005).

Solutions with oleic acid were prepared in 13 distinct concentrations $(0.02,0.06,1.0,1.4,2.0,2.8,3.8,5.0,6.4,8.0,9.8$, 12.0 and $20.0 \mathrm{mM}$ ) (Haryono et al., 2014; Kindleysides et al., 2017; Stewart et al., 2010; Stewart \& Keast, 2012) and added to skimmed milk. Moreover, 5\% gum arabic (instantgum BA, Turkey) and paraffin (Merck, Germany) was added to reduce differences in texture and viscosity, and $0.01 \% \mathrm{w} / \mathrm{v}$ of ethylene diamine tetraacetic acid (EDTA) (Merck, Germany) was also added to solutions to minimize oxidation. The same methodology was used in control sample preparation, minus fatty acid addition. All samples were homogenized, and all solutions for fat taste threshold testing were prepared a maximum of 2 hours before testing to be presented at room temperature.

Three samples were served to the subjects: a sample solution with ascending tastant concentration (i.e., from the lowest to the highest concentration) and two control samples. The subjects were instructed to take the entirety of the $10 \mathrm{~mL}$ sample into their mouth, swirl for approximately 5 seconds, spit it out, and then choose or guess the sample that differs from the rest of them. The minimum concentration at which a subject accurately identifies the different sample (i.e., tastant) from 3 sequential sample sets at one concentration is characterized as the detection threshold (Low et al., 2017; Meilgaard et al., 2006).

The sensory evaluation of solutions was carried out under laboratory conditions to determine fat taste thresholds. Ambient temperature was kept at $20-22{ }^{\circ} \mathrm{C}$. To prevent visual clues, the laboratory windows were covered with curtains and lighting was minimized. The subjects wore nose clips during sessions for taste threshold determination to eliminate confusing non-taste sensory inputs. Before sensory evaluation analysis, water was kept ready for every subject to remove the taste left in their mouths before and after tasting. This procedure helped to remove the taste of the previous solution, preventing it from influencing the taste of the next solution. The subjects were asked to stop eating and drinking at least two hours before the measurement of the thresholds. To prevent the subjects from interacting, they were taken to the laboratory one by one. Subjects were asked to rinse their mouths with water before beginning the task and between each sample set.

Similar to previous publications, sensitivity to oleic acid was treated as a grouping variable and defined as "hypersensitive (high-fat taste sensitivity)" or "hyposensitive (low-fat taste sensitivity)" to taste (Haryono et al., 2014; Keast et al., 2014; Stewart et al., 2011a), and the median (3.8 mM) was designated as the cut-off for detection threshold (Kindleysides et al.,
2017; Pilic et al., 2020; Proserpio et al., 2016; Rodrigues et al., 2017). Subjects with a fat taste threshold $\leq 3.8$ were classified as hypersensitive whereas individuals with fat taste threshold $>3.8 \mathrm{mM}$ were classified as hyposensitive.

\subsection{Statistical analysis}

Statistical Package for the Social Sciences (SPSS) version 22.0 (SPSS Inc., Chicago, IL, USA) was used for data analysis. Food consumption records were analyzed using nutrition information systems software (BeBIS 8.1). Fat taste sensitivity (hyper- or hyposensitive) was used as a grouping variable to explore the differences between categorical (amount of fat/oil used in meals, type of fat/oil, favorite taste and HDI-2015 adherence level) and continuous (weight, BMI, energy intake and fat intake) variables. Data were presented as mean (X) and the standard error of mean (SEM). Categorical data were shown as number (n) and frequencies (\%). An independent two-sample t-test was used to explore the differences between quantitative anthropometric measurements and fat taste sensitivity. In addition, a chi-square analysis was conducted to compare the amount of fat/oil used in meals, the type of fat/oil, the taste preferences of the other basic tastes and HDI-2015 adherence level according to the taste sensitivity. An independent sample t-test was used to investigate the relationship of fat taste sensitivity with HDI-2015 components intake and nutrient intake, based on food consumption records. Pearson's correlation coefficient was used to determine the correlations between data sets on bivariate normal distribution, while the Spearman correlation coefficient was applied when at least one of two variables was not normally distributed. Power analysis was conducted to estimate an appropriate sample size to achieve adequate power. Using G Power Software v3.1.9.4, it was estimated that a minimum sample size of 40 subjects was required to achieve a power of $90 \%$, with an alpha error of 0.05 , at the end of the study. Significance level was set at 5\% $(\mathrm{p}<0.05)$ for all analyses.

\section{Results}

Subjects were $34.83 \pm 1.15$ years (range 23-51 years) of age, and the mean fat taste threshold was $4.29 \pm 0.59 \mathrm{mM}$ (Table 1 ). According to the taste thresholds, 23 subjects (56.1\%) were hypersensitive, and 18 subjects (43.9\%) were hyposensitive. Sweet was the most preferred taste for both hypersensitive and hyposensitive subjects ( $52.2 \%$ and $66.7 \%$, respectively). There was no significant difference in any of the basic taste preferences by fat taste sensitivity $(\mathrm{p}>0.05)$.

More than half of the subjects used sunflower oil as a cooking oil $(65.8 \%)$. There was no significant difference in fat/oil type by fat taste sensitivity $(\mathrm{p}>0.05)$. Subjects preferred moderately fatty meals (73.1\%; $\mathrm{p}>0.05)$.

There was a significant difference in intake of energy (kcal), fat (g), MUFA (g), PUFA (g), EPA (g), DHA (g), linoleic acid (g), arachidonic acid $(\mathrm{g})$ and oleic acid $(\mathrm{g})$ between hypersensitive and hyposensitive individuals $(\mathrm{p}<0.05)$ (Table 2$)$.

Fat taste threshold had a weak positive relationship with fat (g), MUFA(g), PUFA(g), n-3(g) and oleic acid (g) intake ( $\mathrm{r}=0.373$, $\mathrm{r}=0.399, \mathrm{r}=0.351, \mathrm{r}=0.324$ and $\mathrm{r}=0.360 ; \mathrm{p}<0.05$, respectively) 
and a moderate positive relationship EPA (g), DHA (g) and arachidonic acid $(\mathrm{g})$ intake $(\mathrm{r}=0.570, \mathrm{r}=0.526$ and $\mathrm{r}=0.526$; $\mathrm{p}<0.05$, respectively).

The mean HDI-2015 score of the subjects was $3.09 \pm 0.24$ (Table 3). Hypersensitives had a higher mean HDI-2015 score than hyposensitives $(3.52 \pm 0.35,2.55 \pm 0.28 ; \mathrm{p}<0.05$, respectively). More than half of the hyposensitive (66.7\%) subjects displayed low adherence to HDI-2015. In addition, $17.4 \%$ of hypersensitive subjects had high adherence to HDI-2015, while there were no hyposensitive subjects with high adherence $(\mathrm{p}>0.05)$. The percentage of energy from fat and PUFA was higher in hyposensitive subjects $(\mathrm{p}<0.05)$.

The mean weight, BMI, body fat mass $(\mathrm{p}<0.001)$ and mean fat-free mass of hypersensitive subjects were lower than hyposensitive subjects $(\mathrm{p}<0.05)$. The mean waist circumference $(91.52 \pm 1.45 \mathrm{~cm})$ of hypersensitive subjects was lower than that

Table 1. Characteristics of subjects.

\begin{tabular}{|c|c|c|c|}
\hline \multirow{4}{*}{ Individual Data } & \multicolumn{2}{|c|}{ Fat taste threshold classification } & \multirow{2}{*}{ Total } \\
\hline & Hypersensitive & Hyposensitive & \\
\hline & $(n=23)$ & $(\mathrm{n}=18)$ & $(\mathrm{n}=41)$ \\
\hline & $\mathrm{X} \pm \mathrm{SEM}$ & $\mathrm{X} \pm \mathrm{SEM}$ & $\mathrm{X} \pm \mathrm{SEM}$ \\
\hline Fat taste threshold (mM) & $1.48 \pm 0.30$ & $7.87 \pm 0.61$ & $4.29 \pm 0.59$ \\
\hline Age (years) range (23-51 years) & $33.83 \pm 1.37$ & $36.11 \pm 1.97$ & $34.83 \pm 1.15$ \\
\hline EAT-26 range $(3.0-19.0)$ & $11.56 \pm 1.01$ & $14.05 \pm 0.87$ & $12.65 \pm 0.70$ \\
\hline Preference for fat/oil types used in meals & $\mathrm{n}(\%)$ & $\mathrm{n}(\%)$ & $\mathrm{n}(\%)$ \\
\hline Sunflower oil & $15(65.2)$ & $12(66.7)$ & $27(65.8)$ \\
\hline Olive oil & $6(26.1)$ & $2(11.1)$ & $8(19.5)$ \\
\hline Butter & $1(4.3)$ & $1(5.6)$ & $2(4.8)$ \\
\hline Hazelnut oil & $1(4.3)$ & $3(16.7)$ & $4(9.7)$ \\
\hline \multicolumn{4}{|l|}{ Amount of fat/oil used in meals } \\
\hline Fat free & - & - & - \\
\hline Low fat & $13(43.5)$ & $2(11.1)$ & $15(34.1)$ \\
\hline Moderate fat & $10(56.5)$ & $16(88.9)$ & $26(55.9)$ \\
\hline High fat & - & - & - \\
\hline \multicolumn{4}{|l|}{ Taste preferences } \\
\hline Sweet & $12(52.2)$ & $13(66.7)$ & $25(60.9)$ \\
\hline Salty & $7(30.4)$ & $3(19.0)$ & $10(4.3)$ \\
\hline Sour & $3(13.0)$ & - & $3(7.3)$ \\
\hline Bitter & $1(4.3)$ & $2(9.5)$ & $3(7.3)$ \\
\hline
\end{tabular}

Table 2. Energy and macronutrient intake according to the fat taste sensitivity.

\begin{tabular}{|c|c|c|c|c|}
\hline \multirow{3}{*}{ Nutrient Intake } & \multicolumn{2}{|c|}{ Fat taste sensitivity } & \multirow{3}{*}{$\mathrm{p}^{*}$} & \multirow{3}{*}{$\mathrm{r}^{\#}$} \\
\hline & Hypersensitive & Hyposensitive & & \\
\hline & $\mathrm{X} \pm \mathrm{SEM}$ & $\mathrm{X} \pm \mathrm{SEM}$ & & \\
\hline Energy (kcal) & $1992.94 \pm 50.84$ & $2197.77 \pm 73.31$ & 0.023 & 0.285 \\
\hline Carbohydrate (g) & $237.63 \pm 5.51$ & $250.49 \pm 8.83$ & 0.227 & 0.137 \\
\hline Protein $(\mathrm{g})$ & $80.56 \pm 2.17$ & $82.14 \pm 3.42$ & 0.688 & 0.033 \\
\hline Fat $(g)$ & $77.86 \pm 4.28$ & $94.54 \pm 5.00$ & 0.015 & 0.373 \\
\hline Dietary Fiber (g) & $23.86 \pm 0.97$ & $23.88 \pm 1.44$ & 0.986 & -0.046 \\
\hline SFA $(g)$ & $28.74 \pm 2.26$ & $31.56 \pm 1.60$ & 0.316 & 0.241 \\
\hline MUFA (g) & $26.21 \pm 1.58$ & $32.74 \pm 1.95$ & 0.012 & 0.399 \\
\hline PUFA (g) & $15.99 \pm 1.16$ & $21.92 \pm 1.75$ & 0.006 & 0.351 \\
\hline $\mathrm{n}-3(\mathrm{~g})$ & $1.50 \pm 0.15$ & $2.01 \pm 0.22$ & 0.062 & 0.324 \\
\hline EPA (g) & $0.44 \pm 0.06$ & $0.86 \pm 0.08$ & $<0.001$ & 0.570 \\
\hline DHA $(g)$ & $0.19 \pm 0.02$ & $0.38 \pm 0.04$ & 0.003 & 0.526 \\
\hline a-Linolenic acid (g) & $1.26 \pm 0.15$ & $1.58 \pm 0.20$ & 0.213 & 0.302 \\
\hline Linoleic acid (g) & $13.77 \pm 1.04$ & $18.41 \pm 1.58$ & 0.016 & 0.271 \\
\hline Arachidonic acid (g) & $0.32 \pm 0.04$ & $0.60 \pm 0.06$ & 0.001 & 0.526 \\
\hline$n-6 / n-3$ ratio & $10.71 \pm 1.07$ & $10.54 \pm 0.96$ & 0.908 & -0.047 \\
\hline Oleic acid (g) & $23.26 \pm 1.42$ & $28.65 \pm 1.88$ & 0.025 & 0.360 \\
\hline Cholesterol (mg) & $276.83 \pm 23.78$ & $299.84 \pm 25.18$ & 0.514 & 0.043 \\
\hline
\end{tabular}

${ }^{*}$ An independent sample t-test was used to detect differences between nutrient intake levels and fat taste sensitivity based on food consumption records; ${ }^{*}$ Correlation coefficient. 
Table 3. Association between fat taste sensitivity and HDI-2015 components.

\begin{tabular}{|c|c|c|c|c|}
\hline & \multicolumn{3}{|c|}{ Fat taste sensitivity } & \multirow{3}{*}{$\mathrm{p}^{*}$} \\
\hline & Hypersensitive & Hyposensitive & Total & \\
\hline & $(\mathrm{X} \pm \mathrm{SEM})$ & $(\mathrm{X} \pm \mathrm{SEM})$ & $(\mathrm{X} \pm \mathrm{SEM})$ & \\
\hline \multicolumn{5}{|l|}{ HDI-2015 components } \\
\hline Fruits \& vegetables (g/day) & $432.210 \pm 37.11$ & $394.66 \pm 40.66$ & $418.53 \pm 27.29$ & 0.446 \\
\hline Total fat $\%$ of total energy & $34.34 \pm 1.20$ & $38.00 \pm 1.22$ & $35.95 \pm 0.90$ & 0.043 \\
\hline Saturated fatty acid $\%$ of total energy & $12.70 \pm 0.73$ & $12.92 \pm 0.51$ & $12.80 \pm 0.46$ & 0.804 \\
\hline PUFA \% of total energy & $7.15 \pm 0.49$ & $8.92 \pm 0.62$ & $7.93 \pm 0.40$ & 0.030 \\
\hline Free sugar $\%$ of total energy & $5.19+0.37$ & $6.28 \pm 0.64$ & $5.61 \pm 0.35$ & 0.154 \\
\hline Dietary fiber (g/day) & $24.09 \pm 0.97$ & $23.88 \pm 1.44$ & $24.00 \pm 0.82$ & 0.905 \\
\hline Potassium (mg/day) & $3008.70 \pm 117.30$ & $2778.67 \pm 112.20$ & $2907.71 \pm 83.18$ & 0.173 \\
\hline Total Score & $3.52 \pm 0.35$ & $2.55 \pm 0.28$ & $3.09 \pm 0.24$ & 0.040 \\
\hline Adherence Level & $\mathrm{n}(\%)$ & $\mathrm{n}(\%)$ & $\mathrm{n}(\%)$ & $\mathrm{p}^{\#}$ \\
\hline Low & $12(52.2 \%)$ & $12(66.7 \%)$ & $24(58.5 \%)$ & 0.188 \\
\hline Moderate & $7(30.4 \%)$ & $6(33.3 \%)$ & $13(31.7 \%)$ & \\
\hline High & $4(17.4 \%)$ & - & $4(9.8)$ & \\
\hline
\end{tabular}

${ }^{*}$ An independent sample t-test was used to detect differences in HDI-2015 components by fat taste sensitivity, based on food consumption records; ${ }^{*}$ Chi-Square test was used to compare differences in HDI-2015 adherence by fat taste sensitivity.

Table 4. Anthropometric measurements of subjects.

\begin{tabular}{|c|c|c|c|}
\hline \multirow{3}{*}{$\begin{array}{l}\text { Anthropometric } \\
\text { Measurements }\end{array}$} & \multicolumn{2}{|c|}{ Fat taste sensitivity } & \multirow{3}{*}{$\mathrm{p}$} \\
\hline & $\begin{array}{c}\text { Hypersensitive } \\
(\mathrm{n}=23)\end{array}$ & $\begin{array}{c}\text { Hyposensitive } \\
(\mathrm{n}=18)\end{array}$ & \\
\hline & $\mathrm{X} \pm \mathrm{SEM}$ & $\mathrm{X} \pm \mathrm{SEM}$ & \\
\hline Body weight (kg) & $75.36 \pm 1.73$ & $85.19 \pm 2.05$ & $<0.001$ \\
\hline BMI $\left(\mathrm{kg} / \mathrm{m}^{2}\right)$ & $24.53 \pm 0.36$ & $27.58 \pm 0.44$ & $<0.001$ \\
\hline Waist circumference $(\mathrm{cm})$ & $91.52 \pm 1.45$ & $101.94 \pm 1.82$ & $<0.001$ \\
\hline Waist/hip ratio & $0.92 \pm 0.01$ & $0.94 \pm 0.01$ & 0.119 \\
\hline Body fat ratio (\%) & $18.23 \pm 0.72$ & $21.88 \pm 0.72$ & 0.001 \\
\hline Body fat mass (kg) & $13.85 \pm 0.72$ & $19.17 \pm 0.93$ & $<0.001$ \\
\hline Fat-free mass $(\mathrm{kg})$ & $61.44 \pm 1.26$ & $68.29 \pm 2.31$ & 0.015 \\
\hline
\end{tabular}

An independent sample t-test was used to detect differences in anthropometric measurements by fat taste sensitivity.

of hyposensitive subjects $(101.94 \pm 1.82 \mathrm{~cm} ; \mathrm{p}<0.001)$ (Table 4$)$. There was a statistical difference in waist/height ratio between hyposensitive and hypersensitive subjects $(\mathrm{p}<0.001)$. According to the BMI classification, $65.2 \%$ of hypersensitive subjects had a normal BMI (18.50-24.99 $\left.\mathrm{kg} / \mathrm{m}^{2}\right)$. The majority of hyposensitive individuals $(83.3 \%)$ were classified in the overweight group $\left(25.0-29.99 \mathrm{~kg} / \mathrm{m}^{2}\right)$. The difference between groups with regard to BMI classification was statistically significant $(\mathrm{p}<0.05)$.

\section{Discussion}

This study is the first in Turkey to evaluate fat taste sensitivity and diet quality, to our knowledge. This study was conducted to understand the relationship between fat taste sensitivity and diet quality. The diet quality score of hypersensitives was higher than hyposensitives. Interestingly, hypersensitive individuals consumed less fat ( $16.68 \mathrm{~g} /$ day) when compared with hyposensitive individuals. Our results showed that hyposensitive individuals had higher energy and fat intake, as well as lower adherence to HDI-2015 than the hypersensitive individuals.
Each macronutrient - carbohydrate, protein and fat - has distinct characteristics (Carreiro et al., 2016), and any change in macronutrient intake may be associated with disease risks (Shan et al., 2019). Improvement in diet quality may lead to improvement in quality of life (Wanich et al., 2020). Therefore, it is useful to explore the relationship between fat taste sensitivity and diet quality. In our study, the mean HDI-2015 score was higher in hypersensitive subjects than the hyposensitives. It can be concluded that fat taste sensitivity could be related with diet quality of adults. Further studies are needed to investigate the association of the diet quality index with other taste sensitivities.

Dietary fat is an energy-dense macronutrient that contributes to approximately $33-34 \%$ of energy intake in the diets of Turkish adult males (Turkey, 2014). The overconsumption of dietary fats is common due to their palatability, which contributes to negative health outcomes, especially to the development of overweight and obesity (Bolhuis et al., 2016; Golay \& Bobbioni, 1997).

Studies exploring the association of fat taste sensitivity with food intake have attracted attention in recent years. Impaired fat taste sensitivity affects satiety response to fatty acids in the gastrointestinal tract and can lead to increased dietary fat consumption (Asano et al., 2016; Costanzo et al., 2018, 2019; Dramane et al., 2016; Newman et al., 2016a; Stewart et al., 2010, 2011a; Stewart \& Keast, 2012).

The results of the present study have demonstrated the association between the consumption of fatty foods and fat taste sensitivity. Amount and type of fat/oil in meals were determined as per subject statements. More than half of hypersensitive individuals (56.5\%) preferred low-fat meals, while the majority of hyposensitive individuals $(88.9 \%)$ preferred moderate-fat meals $(p<0.05)$. It is likely that increased fatty food intake in hyposensitive individuals is due to attenuated cephalic-phase and post-digestive responses to fatty acid signaling (Costanzo et al., 2017; Frank et al., 2016). 
The main factor affecting fat taste sensitivity is dietary fat intake. It has been determined that the effect of genetics on fat taste sensitivity is nil or minimal (Costanzo et al., 2018). Consumption of a low-fat diet in both obese and lean individuals increases their fat taste sensitivity. Similarly, high-fat diet consumption decreases fat taste sensitivity only in lean individuals, not affecting obese individuals, because obese individuals may have adapted to high-fat meals in their daily diets (Stewart \& Keast, 2012).

There are contradictory studies in the literature that question whether there is a difference in energy and macronutrient intake based on food consumption records by fat taste sensitivity (Keast et al., 2014; Newman et al., 2016b; Stewart et al., 2010, 2011a). There was no difference in terms of energy and macronutrient intake amounts (in $g$ and \%, respectively) based on records of four-day food consumption by Keast et al. (2014) and records of one-day food consumption by Newman et al. (2016b).

However, some studies (Stewart et al., 2010, 2011a) reported lower mean daily energy intake based on food consumption records in hypersensitive individuals. In agreement with the existing literature, we found that the energy intake of hypersensitive individuals was lower than that of hyposensitive individuals $(\mathrm{p}<0.05)$. Human studies have demonstrated less fat consumption in hypersensitive individuals (mean difference of $21 \mathrm{~g} /$ day or $14 \mathrm{~g} /$ day) compared to hyposensitive individuals $(\mathrm{p}<0.05)$ (Stewart et al., 2010, 2011a). Our study reports a similar relationship where the daily fat intake of hypersensitive individuals is lower than hyposensitive ones $(\mathrm{p}<0.05)$.

Stewart et al. (2010) found a lower mean daily intake of MUFA, PUFA and SFA in hypersensitive individuals (20 \pm 2 g, $8 \pm 1 \mathrm{~g}, 19 \pm 2$ g, respectively) according to fat taste sensitivity in comparison to hyposensitive individuals ( $26 \pm 3 \mathrm{~g}$, $12 \pm 1$ g $25 \pm 3$ g, respectively) (p<0.05). Likewise, another study of Stewart et al. (2011a) reported lower MUFA, PUFA and SFA intake in hypersensitive individuals than hyposensitive individuals. Similarly, the results of the present study also indicated lower dietary MUFA, PUFA and SFA intake in hypersensitive individuals compared to hyposensitive individuals $(\mathrm{p}<0.05)$.

Overconsumption of dietary fat involves several factors, such as greater palatability, fat preference and satiety responses (Snoek et al., 2004). Detection of fats and other nutrients during ingestion and digestion is one likely mechanism for regulating energy intake. After consumption, specific receptors in the oral cavity and the gastrointestinal tract detect the presence of fats, prompting the release of certain hormones to decelerate gastric emptying and suppress energy intake. The fact that energy intake is directly affected by the detection of nutrients, especially fatty acids in the digestive tract, suggests that anomalies in nutrient detection mechanisms may underlie overconsumption of fats and excess energy intake, possibly leading to obesity (Newman et al., 2013). Another possible mechanism may be the lower expression of taste receptors in individuals with low fat taste sensitivity, which consequently induces a weakened satiety response after consuming fatty food (Costanzo et al., 2018; Laugerette et al., 2005). Thereby, a person with lower sensitivity could feel less full and consume more energy, regardless of their hedonic system (Costanzo et al., 2018).
In literature, some studies on fat taste sensitivity (Asano et al., 2016; Kindleysides et al., 2017; Stewart et al., 2010, 2011a) have demonstrated that the BMI values of hypersensitive individuals are lower than hyposensitive individuals, while other studies (Stewart \& Keast, 2012; Tucker et al., 2015) have not found an association between fat taste and BMI. In this study, the relationship between fat taste threshold and BMI was found to be moderately positive $(\mathrm{p}<0.01)$. Other studies, such as Stewart et al. $(2011 \mathrm{~b})$ and Asano et al. (2016), suggest the existence of a moderately positive relationship between BMI and fat taste threshold, with similar results to ours.

The literature is conflicting on the relationship of fat taste sensitivity with waist circumference and waist/hip ratio, as with BMI (Costanzo et al., 2017; Dramane et al., 2016). The study conducted by Costanzo et al. did not find any relationship of waist circumference or waist-hip ratio with fat taste sensitivity (Costanzo et al., 2017). Another study conducted with 58 West African subjects reported an inverse correlation between fat sensitivity and waist circumference (Dramane et al., 2016). Our study results also indicated lower waist circumference in hypersensitive subjects than hyposensitive subjects $(\mathrm{p}<0.001)$.

Individuals with lower fat taste sensitivity have impaired ability to detect fat, which may lead to higher consumption of food. Fat has a higher energy density than other nutrient components; therefore, higher fat consumption can cause an increase in body weight (Tucker et al., 2017).

There are some limitations to our study. Firstly, it is important to concede that self-report surveys, while they may not accurately reflect dietary intake, habits or behavior, nonetheless provide a snapshot of dietary habits and are an acceptable method of dietary assessment. Secondly, a larger study population would promote the generalization of HDI-2015 results with respect to fat taste sensitivity. Finally, the subjects of this study were healthy male adults; therefore, their results may not be representative of the general population.

\section{Conclusion}

The study results demonstrated that fat taste sensitivity acted on food intake and diet quality. Decreased fat taste sensitivity may cause increased dietary fat intake, affecting energy intake from fat and diet quality, which in turn impairs quality of life. Further research on other taste qualities conducted with both male and female subjects is needed to understand individual differences in sensory responses and dietary intake.

\section{References}

Asano, M., Hong, G., Matsuyama, Y., Wang, W., Izumi, S., Izumi, M., Toda, T., \& Kudo, T. A. (2016). Association of oral fat sensitivity with body mass index, taste preference, and eating habits in healthy japanese young adults. The Tohoku Journal of Experimental Medicine, 238(2), 93-103. http://dx.doi.org/10.1620/tjem.238.93. PMid:26797054.

Besnard, P., Passilly-Degrace, P., \& Khan, N. A. (2016). Taste of fat: a sixth taste modality? Physiological Reviews, 96(1), 151-176. http:// dx.doi.org/10.1152/physrev.00002.2015. PMid:26631596.

Bolhuis, D. P., Newman, L. P., \& Keast, R. S. (2016). Effects of Salt and Fat Combinations on Taste Preference and Perception. Chemical 
Senses, 41(3), 189-195. http://dx.doi.org/10.1093/chemse/bjv079. PMid:26708735.

Carreiro, A. L., Dhillon, J., Gordon, S., Higgins, K. A., Jacobs, A. G., McArthur, B. M., Redan, B. W., Rivera, R. L., Schmidt, L. R., \& Mattes, R. D. (2016). The macronutrients, appetite, and energy intake. Annual Review of Nutrition, 36(1), 73-103. http://dx.doi. org/10.1146/annurev-nutr-121415-112624. PMid:27431364.

Cartoni, C., Yasumatsu, K., Ohkuri, T., Shigemura, N., Yoshida, R., Godinot, N., le Coutre, J., Ninomiya, Y., \& Damak, S. (2010). Taste preference for fatty acids is mediated by GPR40 and GPR120. The Journal of Neuroscience: The Official Journal of the Society for Neuroscience, 30(25), 8376-8382. http://dx.doi.org/10.1523/ JNEUROSCI.0496-10.2010. PMid:20573884.

Costanzo, A., Liu, D., Nowson, C., Duesing, K., Archer, N., Bowe, S., \& Keast, R. (2019). A low-fat diet upregulates expression of fatty acid taste receptor gene FFAR4 in fungiform papillae in humans: a co-twin randomised controlled trial. British Journal of Nutrition. British Journal of Nutrition, 122(11), 1212-1220. http://dx.doi. org/10.1017/S0007114519002368. PMid:31524116.

Costanzo, A., Nowson, C., Orellana, L., Bolhuis, D., Duesing, K., \& Keast, R. (2018). Effect of dietary fat intake and genetics on fat taste sensitivity: A co-twin randomized controlled trial. The American Journal of Clinical Nutrition, 107(5), 683-694. http://dx.doi.org/10.1093/ ajcn/nqy022. PMid:29659658.

Costanzo, A., Orellana, L., Nowson, C., Duesing, K., \& Keast, R. (2017). Fat taste sensitivity is associated with short-term and habitual fat intake. Nutrients, 9(7), 781. http://dx.doi.org/10.3390/nu9070781. PMid:28726767.

Dramane, G., Gnanka, S., \& Ahyi, V. (2016). Marked differences of fat taste sensitivity between obese and lean subjects. International Journal of Nutrition and Metabolism, 8(1), 1-6.

Frank, G. K., Shott, M. E., Keffler, C., \& Cornier, M. A. (2016). Extremes of eating are associated with reduced neural taste discrimination. International Journal of Eating Disorders, 49(6), 603-612. http:// dx.doi.org/10.1002/eat.22538. PMid:27083785.

Garner, D. M., \& Garfinkel, P. E. (1979). The eating attitudes test: an index of the symptoms of anorexia nervosa. Psychological Medicine, 9(2), 273-279. http://dx.doi.org/10.1017/S0033291700030762. PMid:472072.

Garner, D. M., Olmsted, M. P., Bohr, Y., \& Garfinkel, P. E. (1982). The eating attitudes test: psychometric features and clinical correlates. Psychological Medicine, 12(4), 871-878. http://dx.doi.org/10.1017/ S0033291700049163. PMid:6961471.

Gilbertson, T. A. (1998). Gustatory mechanisms for the detection of fat. Current Opinion in Neurobiology, 8(4), 447-452. http://dx.doi. org/10.1016/S0959-4388(98)80030-5. PMid:9751657.

Golay, A., \& Bobbioni, E. (1997). The role of dietary fat in obesity. International Association for the Study of Obesity, 21(Suppl. 3), S2S11. PMid:9225171.

Haryono, R. Y., Sprajcer, M. A., \& Keast, R. S. (2014). Measuring oral fatty acid thresholds, fat perception, fatty food liking, and papillae density in humans. Journal of Visualized Experiments, (88):51236. http://dx.doi.org/10.3791/51236. PMid:24961177.

Kanauchi, M., \& Kanauchi, K. (2018). The World Health Organization's Healthy Diet Indicator and its associated factors: a cross-sectional study in central Kinki, Japan. Preventive Medicine Reports, 12, 198202. http://dx.doi.org/10.1016/j.pmedr.2018.09.011. PMid:30364851.

Keast, R. S., \& Costanzo, A. (2015). Is fat the sixth taste primary? Evidence and implications. Flavour (London), 4(1), 1. http://dx.doi. org/10.1186/2044-7248-4-5.
Keast, R. S., Azzopardi, K. M., Newman, L. P., \& Haryono, R. Y. (2014). Impaired oral fatty acid chemoreception is associated with acute excess energy consumption. Appetite, 80, 1-6. http://dx.doi.org/10.1016/j. appet.2014.04.022. PMid:24787499.

Kindleysides, S., Beck, K. L., Walsh, D. C. I., Henderson, L., Jayasinghe, S. N., Golding, M., \& Breier, B. H. (2017). Fat Sensation: Fatty Acid Taste and Olfaction Sensitivity and the Link with Disinhibited Eating Behaviour. Nutrients, 9(8), 879. http://dx.doi.org/10.3390/ nu9080879. PMid:28809792.

Laugerette, F., Passilly-Degrace, P., Patris, B., Niot, I., Febbraio, M., Montmayeur, J.-P., \& Besnard, P. (2005). CD36 involvement in orosensory detection of dietary lipids, spontaneous fat preference, and digestive secretions. The Journal of Clinical Investigation, 115(11), 3177-3184. http://dx.doi.org/10.1172/JCI25299. PMid:16276419.

Liu, D., Archer, N., Duesing, K., Hannan, G., \& Keast, R. (2016). Mechanism of fat taste perception: Association with diet and obesity. Progress in Lipid Research, 63, 41-49. http://dx.doi.org/10.1016/j. plipres.2016.03.002. PMid:27155595.

Low, J. Y., Lacy, K. E., McBride, R. L., \& Keast, R. S. (2017). Carbohydrate taste sensitivity is associated with starch intake and waist circumference in adults. The Journal of Nutrition, 147(12), 2235-2242. http://dx.doi. org/10.3945/jn.117.254078. PMid:29070710.

Meilgaard, M. C., Carr, B. T., \& Civille, G. V. (2006). Sensory evaluation techniques: CRC press. http://dx.doi.org/10.1201/b16452.

Newman, L. P., Bolhuis, D. P., Torres, S. J., \& Keast, R. S. (2016a). Dietary fat restriction increases fat taste sensitivity in people with obesity. Obesity, 24(2), 328-334. http://dx.doi.org/10.1002/oby.21357. PMid:26813525.

Newman, L. P., Torres, S. J., Bolhuis, D. P., \& Keast, R. S. (2016b). The influence of a high-fat meal on fat taste thresholds. Appetite, 101, 199204. http://dx.doi.org/10.1016/j.appet.2016.03.011. PMid:26964689.

Newman, L., Haryono, R., \& Keast, R. (2013). Functionality of fatty acid chemoreception: a potential factor in the development of obesity? Nutrients, 5(4), 1287-1300. http://dx.doi.org/10.3390/nu5041287. PMid:23595136.

Okayama, T., \& Watanabe, H. (2019). Association between taste perception, nutrient intake, and mental health in young Japanese women. Nutrition Research and Practice, 13(1), 41-46. http://dx.doi. org/10.4162/nrp.2019.13.1.41. PMid:30788055.

Pilic, L., Lubasinski, N. J., Berk, M., Ward, D., Graham, C. A.-M., Anastacio, V. D. S., King, A., \& Mavrommatis, Y. (2020). The associations between genetics, salt taste perception and salt intake in young adults. Food Quality and Preference, 84, 103954. http:// dx.doi.org/10.1016/j.foodqual.2020.103954.

Poette, J., Mekoue, J., Neyraud, E., Berdeaux, O., Renault, A., Guichard, E., Genot, C., \& Feron, G. (2014). Fat sensitivity in humans: oleic acid detection threshold is linked to saliva composition and oral volume. Flavour and Fragrance Journal, 29(1), 39-49. http://dx.doi. org/10.1002/ffj.3177.

Proserpio, C., Laureati, M., Bertoli, S., Battezzati, A., \& Pagliarini, E. (2016). Determinants of obesity in Italian adults: the role of taste sensitivity, food liking, and food neophobia. Chemical Senses, 41(2), 169-176. PMid:26671250.

Rodrigues, L., Costa, G., Cordeiro, C., Pinheiro, C., Amado, F., \& Lamy, E. (2017). Salivary proteome and glucose levels are related with sweet taste sensitivity in young adults. Food \& Nutrition Research, 61(1), 1389208. http://dx.doi.org/10.1080/16546628.2017.138920 8. PMid:31139039. 
Running, C. A. (2015). High false positive rates in common sensory threshold tests. Attention, Perception \& Psychophysics, 77(2), 692700. http://dx.doi.org/10.3758/s13414-014-0798-9. PMid:25407557.

Shan, Z., Rehm, C. D., Rogers, G., Ruan, M., Wang, D. D., Hu, F. B., Mozaffarian, D., Zhang, F. F., \& Bhupathiraju, S. N. (2019). Trends in dietary carbohydrate, protein, and fat intake and diet quality among US adults, 1999-2016. Journal of the American Medical Association, 322(12), 1178-1187. http://dx.doi.org/10.1001/jama.2019.13771. PMid:31550032.

Snoek, H. M., Huntjens, L., Van Gemert, L. J., De Graaf, C., \& Weenen, H. (2004). Sensory-specific satiety in obese and normal-weight women. The American Journal of Clinical Nutrition, 80(4), 823-831. http://dx.doi.org/10.1093/ajcn/80.4.823. PMid:15447886.

Stewart, J. E., \& Keast, R. S. (2012). Recent fat intake modulates fat taste sensitivity in lean and overweight subjects. International Journal of Obesity, 36(6), 834-842. http://dx.doi.org/10.1038/ijo.2011.155. PMid:21829156.

Stewart, J. E., Feinle-Bisset, C., Golding, M., Delahunty, C., Clifton, P. M., \& Keast, R. S. (2010). Oral sensitivity to fatty acids, food consumption and BMI in human subjects. British Journal of Nutrition, 104(1), 145-152. http://dx.doi.org/10.1017/S0007114510000267. PMid:20196892.

Stewart, J. E., Newman, L. R., \& Keast, R. S. J. (2011a). Oral sensitivity to oleic acid is associated with fat intake and body mass index. Clinical Nutrition, 30(6), 838-844. http://dx.doi.org/10.1016/j. clnu.2011.06.007. PMid:21757270.
Stewart, J. E., Seimon, R. V., Otto, B., Keast, R. S. J., Clifton, P. M., \& Feinle-Bisset, C. (2011b). Marked differences in gustatory and gastrointestinal sensitivity to oleic acid between lean and obese men. The American Journal of Clinical Nutrition, 93(4), 703-711. http:// dx.doi.org/10.3945/ajcn.110.007583. PMid:21310831.

Tucker, R. M., \& Mattes, R. D. (2013). Influences of repeated testing on nonesterified fatty acid taste. Chemical Senses, 38(4), 325-332. http://dx.doi.org/10.1093/chemse/bjt002. PMid:23377369.

Tucker, R. M., Kaiser, K. A., Parman, M. A., George, B. J., Allison, D. B., \& Mattes, R. D. (2017). Comparisons of fatty acid taste detection thresholds in people who are lean vs. overweight or obese: a systematic review and meta-analysis. PLoS One, 12(1), e0169583. http://dx.doi. org/10.1371/journal.pone.0169583. PMid:28060900.

Tucker, R. M., Nuessle, T. M., Garneau, N. L., Smutzer, G., \& Mattes, R. D. (2015). No difference in perceived intensity of linoleic acid in the oral cavity between obese and nonobese individuals. Chemical Senses, 40(8), 557-563. http://dx.doi.org/10.1093/chemse/bjv040. PMid:26232811.

Turkey, Ministry of Health. (2014). Turkey nutrition and health survey 2010 (Report Number, No. 931). Ankara

Wanich, U., Riddell, L., Cicerale, S., Mohebbi, M., Sayompark, D., Liem, D. G., \& Keast, R. S. (2020). Association between food liking and the dietary quality in Australian young adults. Asia Pacific Journal of Clinical Nutrition, 29(1), 166-174. PMid:32229456.

World Health Organization (2020). Body mass index-BMI. Retrieved from: http://www.euro.who.int/en/health-topics/disease-prevention/ nutrition/a-healthy-lifestyle/body-mass-index-bmi. 